\title{
Espaço, pessoa e movimento na socialidade ameríndia: sobre os modos Huni Kuin de relacionalidade ${ }^{1}$
}

\author{
Cecilia McCallum² \\ Universidade Federal da Bahia
}

\begin{abstract}
RESUMO: O artigo explora as práticas huni kuin constitutivas de socialidade, das pessoas e, simultaneamente, das suas relaçóes com o ambiente. Ao criar a si mesmos num sentido material e social em processos intersubjetivos ocorridos em configuraçóes específicas do espaço-tempo, forjam conexôes contingentes de posse entre pessoas e lugares, e criam as condiçóes para abrir clareiras temporárias de espaço humano num mundo vigiado e cuidado por entidades não-humanas. Num primeiro momento, o artigo relembra o empenho das lideranças huni kuin em defender seus direitos de propriedade e insistir na demarcação das terras indígenas, conforme especificado pela legislação brasileira, para o qual usam uma linguagem discursiva não-indígena. O enfoque principal deste ensaio, no entanto, recai sobre as práticas indígenas da vida diária. Explora-se a noção de que, em um sentido proeminente, para este povo da Amazônia, o território não é fixo, mas depende da constante transformação da copresença huni kuin envolvida nas relaçôes entre si e com outras entidades e pessoas do mundo circundante.
\end{abstract}

PALAVRAS-CHAVE: Espaço, socialidade, território, sócio-cosmologia amazônica, Kaxinauá. 
CECILIA MCCALlum. ESPAÇO, PESSOA E MOVIMENTO NA SOCIALIDADE...

"A terra está viva porque os yuxibu vivem nela" Agostinho Manduca (Inkamuru) ${ }^{3}$

Perguntei "quem é o dono?" durante uma das muitas conversas que tive com Pancho, líder dos Huni Kuin de Cana Recreio, assentamento de 150 pessoas localizado no rio Alto Purus, no estado do Acre, Brasil, onde vivi por mais de um ano, entre 1984 e 1985. Nós estávamos falando da grande extensão da floresta e dos lagos situados na jusante da vila, numa área pouco habitada do território indígena. Pancho respondeu que ninguém poderia possuí-la, acrescentando, a título de esclarecimento: "Diusun [Deus] é o dono desta floresta; não as pessoas". Esta sentença não cabia bem com o que eu sabia sobre a participação huni kuin na luta política em prol da proteção das áreas indígenas do estado do Acre. Em verdade, Pancho, assim como outros líderes, era um articulado defensor dos direitos indígenas em relação aos seus territórios, na luta regional contra o processo de colonização. As terras de Recreio e dos outros vilarejos circunvizinhos recentemente tornaram-se pauta de processos legais quanto à demarcação de territórios indígenas (TI) sob a jurisdição brasileira. Nos anos 1970 e 1980, ele desempenhou um papel fundamental no estabelecimento do território indígena (TI) Alto Rio Purus, situado na margem sul do rio. Logo, o que está por trás do seu comentário sobre a "não-posse" da floresta e dos lagos em questáo? O presente trabalho explora as camadas de significados contidos na sua resposta.

$\mathrm{Na}$ época de nossa conversa, em 1984, o sistema econômico estabelecido no Acre, baseado na extração de seringa, estava em franca decadência. A pecuária parecia destinada a substituí-lo. Investidores, especuladores e grileiros estavam interessados em áreas acessíveis via estradas, de onde eles tentaram expulsar os "invasores" (posseiros), geralmente seringueiros que não tinham nenhum conhecimento sobre seus próprios direitos em relação às terras ocupadas. Mesmo quando não sujeitos à 
REVISTA DE ANTROPOLOGIA, SÃO PAULO, USP, $20 \mathrm{I} 5$, V. 58 No I.

expulsão violenta, colonos moradores de regiōes rurais de difícil acesso mal conseguiam sobreviver e, por este motivo, milhares deles estavam migrando em direção às favelas urbanas. Ironicamente, nestas circunstâncias, os povos indígenas da região foram capazes de ocupar e consolidar seu domínio sobre grandes extensóes territoriais - tal como a Ti Alto Rio Purus, na margem sul do rio, doravante TiaP - com relativo sucesso ${ }^{4}$. Eu sabia que restava apenas um assentamento Cariú (não-indígena), composto por dois irmãos e suas respectivas famílias, a residir na foz do rio Chandless, situado dentro da extremidade à jusante do território Alto Purus. Conforme o relato de um dos irmãos, a partida futura deles estava condicionada ao recebimento de uma indenizaçáo por parte da Funai. Todos os demais colonos haviam se retirado do local, a despeito do não oferecimento de compensaçóes financeiras.

Entretanto, alguns Cariú, que residiam na vizinhança da TI situada na margem norte do rio, recusaram-se a respeitar os limites territoriais recém-criados. Pancho relatou, com um ar de satisfaçáo, como ele e seus parentes haviam expulsado um grupo de pescadores, que haviam sido flagrados apanhando uma grande quantidade de peixes de uma lagoa. "Se eles apenas tivessem retirado a quantia suficiente para uma refeição, não teria havido problema algum. Mas eles planejavam comercializar o peixe". Em seguida, ele acrescentou: "Essa terra é nossa e os peixes são nossos também".

Em uma entrevista realizada, transcrita e editada por Aquino e Iglesias e publicada online, Pancho descreveu esses eventos como parte da sua bem sucedida contribuição para o assentamento do TIAP. Na seção intitulada "Tirando os brancos", Pancho detalha como conseguiram tirar os seringalistas e seringueiros, para os quais falaram "índio tem direito sim, nós somos donos da terra". Nota que "quando ganhamos a terra, a Funai indenizou eles. Acabou o problema.” E em seguida, conta: 
CECILIA MCCALlum. ESPAÇO, PESSOA E MOVIMENTO NA SOCIALIDADE...

\begin{abstract}
Outros brancos moravam do outro lado do rio Purus. Vinham de lá pra cortar seringa. Estragavam nossas seringueiras, derrubavam nossas madeiras pra fazer canoa. Pegavam nosso peixe. Por isso, briguei muito nesse tempo. Trouxe sessenta índios e quebramos todas as canoas que estavam dentro do lago. Então falei: "Se vier, nos amarra no pé de taxi. Bate em nós pra ver se é homem!". Ficaram revoltados com a gente. Eu falei: "Vai dar parte para ver quem tem mesmo direito!”. Não mexeram mais. [...] Hoje, são muitas aldeias novas. Era preciso nos dividir pra segurar nossa terra. Antes o branco invadia nossa terra, entrava em nossos lagos, pegava nosso peixe, botava canoa no lago para mariscar. Onde estou morando hoje, branco vem mariscar. Eu deixo, é vizinho, é pra criar filho deles, não é pra ramo de vida, pra vender. (Kaxinawá, 2006).
\end{abstract}

Então, em que sentido, para um Huni Kuin, um território tanto pode ser propriedade exclusiva de um grupo social como também algo a ser excluído da categoria de coisas ou pessoas que podem ter um dono ( $i b u$ ) humano? Contextualizadas historicamente, as razóes para se reivindicar a titularidade de um "território" em contraposição aos interesses dos colonos e dos invasores predatórios são claras o bastante. Mas o que há nas afirmações feitas por Pancho sobre ser Diusun (Deus) o único apto a possuir toda a extensão de florestas, lagos e cursos d'água, extensão esta referida na língua portuguesa como sendo um "território"?

Há mais em jogo do que uma troca de "discursos" por parte do meu interlocutor. Claro, as pessoas indígenas podem se expressar em línguas nacionais e adotar estrategicamente distintos discursos forjados dentro de estruturas de poder não-indígenas, bem como lidar criativamente com processos históricos que são produtos de regimes de verdade europeus (Albert, 2005; Brown, 1993). Esta empresa é muito séria e a compreensão de Pancho sobre a língua portuguesa e a legislação brasileira é evidente no extrato citado acima, que, mesmo sendo uma versáo editada 
REVISTA DE ANTROPOLOGIA, SÃO PAULO, USP, $20 \mathrm{I}$, V. 58 N $\mathrm{N}^{\mathrm{O}} \mathrm{I}$.

pelos antropólogos que o entrevistaram, em muito parece fiel à própria maneira de Pancho se expressar. Embora alfabetizado, ele não possuía mais que poucos anos de escolarização; porém, ele habilmente utilizava vocábulos tomados de empréstimo do português, bem como reinventava ideias importadas como parte das suas atividades políticas hodiernas (McCallum, 1990, 1996b)5. Ao lidar com os não Huni Kuin, ele poderia falar dos "direitos" e do regime de "propriedade", nos marcos da lei, lidando com estes Nawa (forasteiros) no que ele entendia ser os seus próprios termos. Desde a sua morte, o engajamento huni kuin com os discursos e epistemologias nacionais se intensificou. Durante a primeira década do milênio, o número de estudantes indígenas que buscam se tornar especialistas em diferentes domínios do saber e da aprendizagem euro-americana (tais como a Linguística, o Direito ou a Medicina) tem aumentado significantemente. Pode-se mesmo dizer que as geraçóes atuais dos Huni Kuin já não fazem mais um uso sobretudo pragmático ou estratégico de idiomas nacionais e de estilos de conhecimento; estáo, isto sim, imersos em um contexto fenomenológico que faz dos processos ontogenéticos uma espécie de engajamento poliontológico ${ }^{6}$.

Neste artigo, não me concentrarei no uso pragmático e criativo de discursos de origem não-indígenas pelos líderes indígenas ao procurar explorar essa aparente contradição nas reivindicaçôes em torno da propriedade da terra. Os contextos onde se utiliza a linguagem discursiva de origem brasileira ou transnacional é distante dos mundos vividos pela maioria dos parentes das lideranças: é sobre esses mundos que o artigo se debruça. Adotarei uma perspectiva analítica que enfoca a vida cotidiana, destacando, pois, a relação huni kuin com o mundo circundante, incluindo os espaços físicos que podem ser referidos pelo termo território, mas não partindo dos pressupostos ligados ao conceito. Desse modo, deixarei para outra ocasião a discussão dos importantes processos de "territorialização", conforme definido na apresentação do presente 
CECILIA MCCALlUM. ESPAÇO, PESSOA E MOVIMENTO NA SOCIALIDADE...

dossiê, no rastro de Pacheco de Oliveira (1998), para me concentrar nos processos de vivência a que os organizadores se referem por meio da noção de "territorialidade".

A territorialidade em destaque aqui, no entanto, é aquela produzida nos pequenos atos e encontros do dia-a-dia, e não aquela que emerge de eventualidades ou processos históricos. As territorialdades em foco são geradas mais pelos processos micro-históricos que pelas imposiçóes históricas de escala maior. $\mathrm{O}$ argumento que eu proponho é o seguinte: as atividades cotidianas e corriqueiras dos Huni Kuin constituem a "posse" da terra como algo contingente. Por sua vez, esta qualidade contingente é um efeito da dependência das práticas de seres humanos vivos (Huni Kuin) sobre os não-humanos, a saber, o envolvimento huni kuin com os seus semelhantes e com as entidades do mundo ao seu redor. Os processos pelos quais o gênero, a pessoa e a socialidade são criados informam o modo pelo qual a posse da terra é constituída, na medida em que arranjos particulares de parentesco emergem do engajamento entre, por um lado, as formas e expressóes sempre mutáveis e diversas destes espaços, e, por outro, pessoas humanas e não-humanas. Assim, as pessoas, os corpos e o ambiente estão mutuamente imbricados, ou seja, as conexôes entre eles são internalizáveis e mutáveis. O produto geral destes processos, na forma de sedimentaçóes ao longo prazo dos efeitos corporais e materiais destas imbricaçôes, é uma relação coletiva que pode ser utilmente justaposta com as relaçóes pressupostas pelo conceito euro-americano de "território". Porém, eles não se traduzem plenamente como tal.

No Brasil, o regime ontológico hegemônico, no âmbito da esfera jurídica, trata a terra como algo objetivo, fixo e externo aos seres humanos - uma coisa que pode ser alienável, em se tratando de uma propriedade privada, ou inalienável, como no caso das áreas indígenas. Estes dois conjuntos de relacionamento entre humanos e espaços objetificados não 
REVISTA DE ANTROPOLOGIA, SÃO PAULO, USP, $20 \mathrm{I}$, V. $58 \mathrm{~N}^{\mathrm{O}} \mathrm{I}$.

servem para expressar os tipos de relaçóes que a experiência huni kuin conceitualiza em suas atividades cotidianas. Em suma, o conceito brasileiro de território violenta as premissas sobre as quais a prática huni kuin se assenta. Postulo, portanto, a titulo de hipótese, que quando Pancho afirmou ser "Deus" o único dono da terra, ele tinha em mente o que "é evidente" 7 para todos os Huni Kuin: o entendimento de que o ambiente terrestre, para a sua própria existência, está imbricado e é dependente da socialidade vivida. É esta a proposta a ser explorada e fundamentada no corpo deste artigo ${ }^{8}$.

Isto exige, como um passo preliminar, que deva ser dado a devida importância ao modo de pensar e fazer huni kuin que, na mirada filosófica, pode ser denominado de uma fenomenologia própria. Do ponto de vista da vida cotidiana huni kuin, o relacionamento é criado por meio do engajamento com o mundo fenomenal - ou seja, com objetos e seres que, para os Huni Kuin, são concomitantemente materiais e imateriais, visíveis e invisíveis; a forma e a aparência dependem da condição corporal (consciente, inconsciente) do observador. As relaçóes de proximidade nunca são dadas a priori, pois precisam ser construídas materialmente e reafirmadas sempre. A natureza constantemente emergente do parentesco é tomada como uma característica central da vida cotidiana. De fato, a necessidade de fabricá-la motiva o trabalho a ser feito a cada dia, e nisto os Huni Kuin não são diferentes dos outros povos amazônicos. Muito tem sido publicado recentemente sobre a qualidade mutável do parentesco na Amazônia indígena. Normalmente, os analistas se aproximam deste fenômeno através do enfoque nos aspectos corporais e interpessoais a ele correlacionados, seguindo o caminho estabelecido pelos estudos clássicos de parentesco, as releituras feministas e outras críticas, e na rica e crescente literatura etnográfica sobre os povos amazônicos e outras populaçôes ameríndias. Sem dúvida, o corpo, ou as rupturas e as conexôes entre os corpos, é um importante ponto de partida quando se procura 
CECILIA MCCALlUM. ESPAÇO, PESSOA E MOVIMENTO NA SOCIALIDADE...

compreender os diversos modos de relacionamento nesse universo. O investimento recente nas perspectivas fornecidas pelos estudos do "novo parentesco" (Carsten, 2004) contribuiu para este desenvolvimento e levou a uma amazonizaçáo de conceitos e modelos retirados da literatura melanésia, tais como a fractalidade e a noção de divíduo. Estas novas abordagens têm sido associadas à "virada ontológica" no âmago da teoria antropológica ${ }^{10}$. Frequentemente, na robusta e florescente literatura produzida no Brasil, as ideias são retrabalhadas à luz de um sofisticado interrogatório da etnografia, cuja fortuna analítica em muito se deve ao trabalho de Lévi-Strauss, especialmente as suas publicaçóes mais tardias.

Nestes estudos, a preocupação com a forma (as estruturas dinâmicas conceituais a dirigir a fabricação do parentesco) suplanta o que é colocada por vezes como a equivocada ênfase na "substância" característica de alguns projetos analíticos concorrentes ${ }^{11}$. A insinuação é que esta noção de substância provém da tradição analítica euro-americana, e que seria repleta de conotaçóes subsidiárias de um cartesianismo mal aplicado, oferecendo uma leitura demasiado simplista do entendimento indígena sobre os aspectos materiais da constituição da socialidade. Não é minha intenção discutir abordagens teóricas distintas ou julgar os seus méritos ou falhas aqui. Procurarei realinhar os termos do debate à luz da minha compreensão dos modos de pensar dos Huni Kuin em McCallum (2013). No entanto, é preciso notar que taxar grosso modo de "substantivistas" as abordagens que focalizam a vivência de relações de parentesco ou as experiências de contatos com os seres e fenômenos do mundo cotidiano é perder de vista um aspecto central do pensamento indígena. Colocado de outra forma, a preocupação para com a investigação da ontologia indígena, a partir de uma perspectiva pós-kantiana, tem levado a uma grande ênfase nas formas lógicas de constituição do parentesco em nível ontológico, ao ponto de tratá-lo como que distanciado da práxis indígena e das compreensóes sobre matérias etnograficamente 
REVISTA DE ANTROPOLOGIA, SÃO PAULO, USP, $20 \mathrm{I}$, V. 58 N $\mathrm{N}^{\mathrm{O}} \mathrm{I}$.

específicas. A rejeição às abordagens ditas "substantivistas", em favor das "ontológicas", levou a uma negligência quanto ao papel central desempenhado pela fenomenologia indígena no tocante à constituição prática do parentesco ${ }^{12}$. Entretanto, a epistemologia indígena insiste em proclamar que os sentidos constituem e dáo a conhecer a realidade vivida como um processo corporal, no qual visôes, cheiros, palavras e sabores são integrados materialmente na carne e no osso da pessoa (Kensinger, 1995; McCallum, 1996a; Lagrou, 1998, 2007; Viveiros de Castro, 1996, 1998) ${ }^{13}$. Atualmente, este insight, que foi bem articulado nos anos 1990, corre o risco de se perder no meio do caminho, caso a trilha ontológica seja seguida com um excesso de entusiasmo e de maneira acrítica, deixando de lado o ponto de vista da fenomenologia indígena.

\section{Criando lugares}

De modo a apreciar a fenomenologia huni kuin, pode-se começar pelo ambiente por eles habitado e os conceitos que expressam algo de suas experiências vividas. $\mathrm{Na}$ região do Brasil atravessada pelo rio Purus, a floresta se espalha sobre a terra de barro ondulante, envolve lagos e mananciais, e adapta-se aos pântanos e extensôes de solo arenoso ou argila fértil. O terreno é plano e sem montanhas ou declives significativos para canalizar e direcionar o fluxo dos rios, de forma que estes cursos de água se enrolam e se curvam sobre si mesmos sem parar à medida que lentamente encontram o seu caminho em direção à Amazônia. A formação geológica desta região do Alto Purus é praticamente desprovida de rochas; logo, as estaçóes do ano e a presença de chuvas torrenciais ou de sol escaldante determinam a dureza ou suavidade da terra. A vegetação rasteira é densa, dificultando o avanço sobre a floresta que é grossa. $\mathrm{O}$ ar se espalha para além do horizonte numa expansão horizontal ininterrupta. 
CECILIA MCCALlum. ESPAÇO, PESSOA E MOVIMENTO NA SOCIALIDADE...

Mas os Huni Kuin não a veem como deitada. Pelo contrário, enxergam-na a partir da sua verticalidade. Para eles, a floresta estende-se para cima, em direçáo ao céu, e é esta a qualidade que $n i$, o termo para floresta, expressa. Ni significa "em pé" ou "andar" em sua forma verbal. Então, em vez de nos referirmos a uma horizontalidade passiva, falemos da infinidade de árvores que parecem capturar a essência de algo verticalmente móvel e personificado. E, de fato, árvores e outras plantas têm em muitos casos agência e antropomorfismo; algumas são classificadas como yuxin (pessoas/espíritos). As maiores árvores são yuxibu (poderosos espíritos monstros) e também habitaçóes para yuxin. Elas fornecem conexôes com os níveis superiores do cosmos habitados pelos mortos e outros espíritos benevolentes. Estes yuxibu são os invisíveis, mas imensamente poderosos $i b u$ ou guardiães do $n i$ e de muitos outros seres não humanos ${ }^{14}$.

Não há um termo huni kuin capaz de traduzir adequadamente a noção de "terra" ou "território". Ambos os verbetes, tanto na língua portuguesa, quanto na inglesa, parecem evocar a qualidade de algo eterno, estacionário, uma fixidez que contrasta com a transitoriedade da vida biológica que a Terra impassível suporta. Em huni kuin, mai significa "Terra", "solo" e "barro"; contudo, este termo não é utilizado para se referir a extensóes de propriedade de terra. Diferentes lugares têm distintos tipos de mai - o tipo de mai encontrado em um bai kuin (roçado aberto em terra alta), por exemplo, difere daquele característico dos roçados plantadas nas áreas ribeirinhas. Apesar de uma mae (aldeia) adquirir uma áurea de permanência após alguns anos de habitação, a forma verbal deste termo significa "mudar de casa”. Aldeias não são propriedades dos líderes masculinos e femininos (xanen ibu e ainbu xanen ibu, respectivamente), embora eles sejam responsáveis conjuntamente pela organização e manutenção do espaço. As casas, bem como os roçados, das terras elevadas ou ribeirinhas, possuem $i b u$, um termo que pode ser 
REVISTA DE ANTROPOLOGIA, SÃO PAULO, USP, $20 \mathrm{I} 5$, V. 58 No I.

glosado como "dono", mas que implica um "cuidador", uma pessoa com responsabilidade por alguma coisa ou ente, que efetua uma criaçáo dos corpos das plantas produzidas ou das habitaçóes. Ibu tem fortes conotaçôes de uma relação assimétrica de parentesco, pois significa mãe ou pai, igualmente A noçáo de bai ressoa com o conceito de criação; assim, $b a$-é uma forma verbal que significa tanto "procriar" e "cozinhar" e está usada para referir a criatividade feminina que necessita ser desencadeada, possibilitada e estimulada nas relações conjugais (McCallum, 2001). Somente as pessoas casadas podem ser $i b u$ de jardins e casas e, portanto, o termo implica a relação de gênero basal na constituição de socialidade vivida $^{15}$. Os celibatários colaboram com os casados, ajudando-os nos processos criativos, podendo, após o casamento, se tornar $i b u$ de algum terreno para construir uma habitação, ou trecho de terra ou barranco de rio para uma plantação, através do reconhecimento por parte dos aldeôes (algo acordado em reunióes) do seu envolvimento físico no trabalho sobre esses espaços. Tais direitos decorrem da organização do trabalho, mas, a longo prazo, expiram uma vez que o jardim se exaure e a casa é abandonada após uma morte ou mudança por outro motivo e caia na ruína (McCallum, 2001). Nestes casos, os espaços brevemente voltam a ser floresta. Assim, mesmo que a terra firme que suporta as casas e as plantas cultivadas sejam uma espécie de "propriedade" - ou seja, elas têm um $i b u$-, há um senso de fugacidade na permanência das pessoas em um espaço. De fato, em 1994, a maior parte dos 150 moradores do Recreio do Alto Rio Purus com quem eu morara em 1984 havia saído e se estabelecido em novas aldeias acima ou abaixo do curso do rio. Em resumo, pode-se dizer que os espaços habitados no plano terrestre do cosmos são, ao contrário de seus primos homônimos de tijolo e argamassa, definidos por sua transitoriedade e maleabilidade.

É impossível pensar na terra sem a referência ao $n i$ - a floresta "em pé" - ou aos espaços aquosos que, por assim dizer, quebram a aderência 
CECILIA MCCALlUM. ESPAÇO, PESSOA E MOVIMENTO NA SOCIALIDADE...

monótona da infinidade de árvores sobre a paisagem. Lagos são lugares ameaçadores, ricos não somente em peixes, mas também em jacarés, alguns dos quais atingem proporçóes monstruosas. Como as maiores árvores da floresta e as gigantes anacondas que ocasionalmente se encontram a nadar ou a tomar sol à beira da água, estes enormes animais, ou quaisquer outros de sua prole, são seres espirituais conhecidos como yuxibu. Eles são o ibu dos reinos aquosos que habitam e vivem nas profundezas dos lagos, ou nas piscinas de grande profundidade ao longo do curso de um rio, que ameaçam tragar os passageiros de canoas viradas ou os nadadores descuidados ${ }^{16}$. Eles representam a ameaça constante de descida vertical ao submundo, um lugar de água corrente onde os habitantes marinhos enxergam a si mesmos como humanos e como afins em potencial dos Huni Kuin. Mas, se os lagos e os turbilhóes representam uma ameaça constante de uma descida vertical sem volta, ou seja, a passagem irreversível da vida para a morte, os cursos de água que cortam a floresta permitem uma transitoriedade reversível. Rios e córregos facilitam tanto a separação entre distintos espaços humanos e nawa (estrangeiros e inimigos) esculpidos entre grupamentos de árvores verticalizadas, como também garantem a renovação das conexóes entre os seres humanos vivos. Eles são caminhos líquidos ao lado ou por meio dos quais as pessoas podem caminhar, bem como podem transitar com barcos ou canoas a remo ou embarcaçôes motorizadas (quando a gasolina está disponível). Rios são simplesmente referidos como jene (líquido); são, pois, caracterizados pelo fluxo constante de água, os quais são tratados pelos Huni Kuin nos termos de uma analogia com os seus poderes de conectividade. Assim, o termo para correnteza de um rio - bai - é o mesmo utilizado para caminho (bem como para jardim). Em suma, os rios são os meios - como também são as metáforas - de movimento e conexão. 
REVISTA DE ANTROPOLOGIA, SÃO PAULO, USP, $20 \mathrm{I} 5$, V. $58 \mathrm{~N}^{\circ} \mathrm{I}$.

\section{Fazendo caminhos}

Além da referência à correnteza do rio, o termo bai também expressa os traços ou efeitos que os organismos ativos deixam sobre a terra. Fazer uma roça ou bai requer um trabalho extenso, coletivo e individual, envolvendo a colaboração macho-fêmea, para transformar a floresta em trechos de plantas cultivadas. O processo também toma a forma de uma transferência de propriedade dos frutos da terra, dos espíritos para os humanos. As entidades originais responsáveis pelas árvores e plantas, o ni yuxin ou o yuxibu, no caso de todas as grandes árvores que devem ser abatidas, devem ser separadas dos corpos das plantas e árvores. Os homens responsáveis por destruí-las tornam-se ibu (dono/responsável) dos espaços por ele queimados. Contudo, a pessoa a quem a posse da bai é "definitivamente" atribuída é a mulher que lavra a terra, aquela que dedicará vários anos de sua vida ao seu cultivo. Na medida em que os corpos das plantas crescem e se fortalecem, o seu status como $i b u$ (dona/cuidadora) ganha força. A transformação do ni em bai kuin (roçado verdadeiro) afeta, então, as relaçôes de transferência entre as pessoas (os Huni Kuin descrevem yuxin como gente, pessoa) e os corpos que são criados em espaços conhecidos como bai. Assim, dizer que uma pessoa é a dona de uma roça significa afirmar que ela é a sua criadora, assim como os pais são os fabricadores dos seus filhos. Em outras palavras, yuxin e seres humanos não são tanto $i b u$ no sentido de dono da terra, mas sim ibu dos produtos das plantas e árvores cujas raízes estão fincadas na terra, $i b u$ no sentido de cuidadores de corpos vivos, sobre os quais têm uma medida de controle.

Um homem começa a estabelecer suas trilhas de caça ao lado de córregos ou através de sendas deixadas por antas ao forçarem seu caminho através da floresta (Kensinger, 1995: 13) ${ }^{17}$. Com o passar do tempo, os caçadores e seus companheiros ocasionais limpam estas trilhas de quaisquer obstáculos, ampliando-as, construindo cabanas de caça perto de grandes 
CECILIA MCCALlUM. ESPAÇO, PESSOA E MOVIMENTO NA SOCIALIDADE...

árvores frutíferas, cortando troncos para fazer pontes sobre os córregos, retirando as tiras das suas cascas para fabricar alças de cabeça, e assim por diante, de modo que estas atividades físicas definem os caminhos e os alteram. A rota do seringueiro também tem a sua existência continuada e redefinida ao longo do tempo. Da mesma forma, o corpo de um homem é em si continuamente alterado e formado por suas experiências ao longo desses caminhos e do trânsito pela floresta. Sua visão, audição, olfato e tato lhe permitem agir de tal forma que geram efeitos sobre a floresta circundante, mas, desde que esses sentidos estejam enraizados em diferentes partes do corpo, como os olhos, ouvidos e mãos, eles próprios são alterados por suas experiências. Em particular, de acordo com os informantes de Kensinger, um caçador adquire os conhecimentos e as habilidades que são inscritas na pele e da mão através da interação com a miríade de seres, plantas e árvores encontradas durante o processo de construção de rotas.

A caça bem-sucedida requer um conhecimento considerável [...] das características comportamentais dos animais caçados com base na observação. Este [...] é "o conhecimento da pele", bichi una, como é todo o conhecimento do mundo natural. Quando perguntei porque isto não era o "conhecimento do olho" [...] eles me disseram que este era o conhecimento sobre o espírito do corpo da selva, yudabake yushin (Kensinger, 1995: 239-240) ${ }^{18}$.

A ideia de que os caçadores são os ibu dessas trilhas e do território em torno delas expressa a noção de que quando uma pessoa produz um efeito material acumulado sobre a matéria - tanto animada, quanto inanimada -, ele ou ela está em um processo de constituição de uma relação ibu - uma relaçáo assimétrica que possui, concomitantemente, aspectos de posse e de parentesco. Isto replica de algumas maneiras o relacionamento entre yuxibu, os que são os invisíveis $i b u$ dos dois planos 
REVISTA DE ANTROPOLOGIA, SÃO PAULO, USP, $20 \mathrm{I}$, V. 58 N $\mathrm{N}^{\mathrm{O}} \mathrm{I}$.

do cosmos, que são acessados e por onde trafegam os humanos (isto é, os planos do estado material ordinário) - os cursos de água, os lagos e a floresta. Yuxibu também são os guardiães do terceiro plano cosmológico, os céus, cujos habitantes aviários os seres humanos costumam caçar.

A predação é um modo masculino (mas não necessariamente exclusivo aos homens) de interação com os seres nestas três zonas. Quando os homens huni kuin de diferentes aldeias em APIA criaram um novo tipo de caminho, no final de 1980, uma trilha a cortar a floresta, de modo a demarcar as fronteiras do território indígena, eles viveram esta experiência como uma grande expedição de caça. Resolvi perguntar a alguns dos participantes sobre suas experiências. Ao invés de falar sobre o árduo trabalho que, sem dúvida, estava envolvido em toda empresa, eles entusiasticamente mencionaram os diferentes tipos de bichos vistos e caçados durante as semanas e meses do processo de demarcação. Da mesma forma, nos desenhos por mim coletados em 1985, feitos por homens huni kuin para ilustrar a demarcação do território do rio Jordão, as figuras sempre se referiam aos animais de caça consumidos, e nunca o grupo de trabalho ou a demarcação em si mesma.

A caça sempre envolve a destruição e a transformação dos corpos que estão atrelados a seus construtores e criadores (seus ibu) ${ }^{19}$. Matar significa se engajar em uma relação com esses "donos" mediada através dos corpos convertidos em carne para o consumo e dessa forma apropriados. Porém, a caça e a matança não acontecem em um espaço neutro. A floresta não é uma parte da "natureza", mas sim uma constelação de zonas de habitação e responsabilidade criadas e povoadas por seres, muitos dos quais os Huni Kuin julgam ser "pessoas". Quando os humanos alteram o meio ambiente, criando trilhas e abrindo clareiras, logo eles investem na apropriação parcial destes lugares e na possibilidade da transformação, revelação ou expulsão destes seres. É como se estivessem a deslocar os $i b u$ originais juntamente com seus tutelados 
CECILIA MCCALlUM. ESPAÇO, PESSOA E MOVIMENTO NA SOCIALIDADE...

e parentes, ou como se estivessem a tornar mais nítidas as distinçóes e distâncias entre os domínios visíveis e invisíveis dos regimes de controle, criatividade e responsabilidade.

Está claro, portanto, que existe uma relação de constituição mútua entre os caminhos e os corpos humanos em contextos como a caça. Uma lógica semelhante opera no tocante à visita a outras casas ou aldeias, ou nos trajetos de ida e volta aos roçados. Os corpos humanos de homens e mulheres produzem e mantêm trilhas pela floresta (bai) enquanto cuidam de sua rotina de trabalho cotidiano, vêm e vão, não apenas de roças, mas também de expediçóes de pesca e de caça ou (no passado) de viagens para a coleta do barro que era utilizado na cerâmica. A bai ou correnteza dos rios, por outro lado, não deve sua existência à ação humana.

Até este ponto, a discussão sobre as vias terrestres ou lagos e cursos de água concentrou-se nas formas que facilitaram as conexôes e desconexôes entre seres humanos e não-humanos (horizontal, no primeiro caso; vertical, no último). Todavia, ambos são rotineiramente utilizados por pessoas para forjar conexóes com outros seres humanos, um tema tratado na próxima seção, que retoma o enfoque na socialidade vivida.

\section{Fazer visitas $^{20}$}

Visitar significa conectar dois lugares e, portanto, dois corpos de parentes. A natureza corporal do parentesco é capturada na expressão nukun yura, que se refere aos parentes homens e mulheres, em um sentido coletivo, significando literalmente "nosso corpo". O veráo é a época perfeita para visitar parentes distantes ou outro tipo de yura. O rio fica raso e as praias esticam-se ampla e firmemente, permitindo que os viajantes caminhem ao redor das curvas do rio, com uma ou duas mulheres ou mesmo as meninas assumindo o comando da canoa. As turvas águas 
REVISTA DE ANTROPOLOGIA, SÃO PAULO, USP, $20 \mathrm{I} 5$, V. 58 No I.

amareladas do rio Purus fluem gentilmente, permitindo àqueles que empunham os remos ou paus utilizados para empurrar as canoas avançar sem muito esforço. A estação seca, entre meados de maio a setembro, é o momento em que famílias inteiras tomam parte em expediçôes para encontrar parentes distantes, viajando dias ou semanas para se juntar a eles para uma visita que pode durar vários meses, ou mesmo para estadias mais prolongadas que possam resultar em mudança permanente e novos casamentos. Este é o período em que as mulheres realizam expediçóes coletivas curtas, que começam no raiar do dia e terminam no começo da noite, quando elas retornam às suas aldeias ${ }^{21}$.

Quando as mulheres deixam suas casas para visitar a residência de outra mulher, dizem "En bai kai", ("Eu vou visitar"). O principal objetivo dessas visitas é comer os alimentos produzidos por amigos e parentes, de modo que uma mulher pode comentar "En baka pikai" ("Eu vou comer peixe"), ou qualquer outro alimento que ela sabe que faz parte da despensa dos seus anfitrióes. As pessoas costumam visitar outras famílias dentro de sua própria mae e embarcam em uma expediçáo para outra aldeia apenas ocasionalmente. No caso de visitas interaldeias, as mulheres vão não apenas para comer, mas também em busca de presentes, alimentos crus, especialmente para trazê-los de volta para casa. As visitas, desta forma, possuem algo da natureza predatória, na medida em que os anfitriōes são obrigados a ser generosos, servindo refeiçôes e concedendo presentes aos visitantes. Eles correm o risco de perder os frutos de suas recentes atividades produtivas nos jardins, no rio e na floresta, se estes não forem suficientemente escondidos quando os forasteiros aportam em suas casas e sobem as escadas em direção aos compartimentos onde estão guardados os suprimentos. Só no futuro, em uma visita de retorno, eles poderão compensar essa perda. Assim, através do dar e da apropriação dos frutos do seu próprio trabalho, as mulheres de diferentes aldeias criam ou recriam laços sociais com os Huni Kuin que são seus "outros". 
CECILIA MCCALlum. ESPAÇO, PESSOA E MOVIMENTO NA SOCIALIDADE...

As duas maiores aldeias do Purus em 1984-1985, Recreio e Fronteira, ficavam localizadas cerca de duas horas de intervalo uma da outra, quando a viagem era feita em canoas a motor. Os habitantes de cada aldeia tinham histórias recentes distintas, mas uma origem comum de um grupo de população que habitava a região do rio Muru no início do século xx. O povo de Recreio recentemente havia migrado rio abaixo em direção ao Brasil depois de décadas residindo no Peru, nas margens do rio Curanja, uma das cabeceiras do Purus, enquanto o povo de Fronteira havia chegado do rio Envira a partir do Ocidente, onde os homens haviam trabalhado como seringueiros, sempre endividados, para os patrôes brasileiros. Contava-se em cada assentamento cerca de 100 pessoas (os índices populacionais sempre oscilavam para mais ou para menos, na medida em que visitantes migravam, novos aldeães nasciam, outros tantos morriam, e assim por diante). Aliados políticos na luta pela terra (ou Área Indígena, nos termos legais), os habitantes tinham ajudado uns aos outros substancialmente nos últimos anos, quando os dois vilarejos estavam sendo estabelecidos. Como reflexo de suas trajetórias históricas distintas, no entanto, estilos de interação diferem sutilmente entre eles, e há certas diferenças linguísticas. Embora a língua huni kuin seja falada nas duas aldeias, havia diferenças de sotaque e no uso de figuras de linguagem. Em geral, cada aldeia mantinha a si mesma. Uma corrente de hostilidade latente parecia pairar sob a superfície durante os encontros ocasionais entre os moradores dessas duas aldeias, porém, ela foi substituída pela ética formal de interação e pela renovação periódica das relaçôes pacíficas.

Visitas envolvem uma mistura de festa e formalidade. Para visitar Fronteira no verão, as moradoras de Recreio acordavam de madrugada, reuniam as crianças, chamavam o cão favorito, pegavam os facóes, carregavam cestos e trouxas de roupas limpas e, ao chamar suas companheiras para a viagem de um dia, caminhavam até a entrada do vilarejo. A convite de uma das partes, por vezes, no final do veráo, elas podiam fazer uma 
REVISTA DE ANTROPOLOGIA, SÃO PAULO, USP, $20 \mathrm{I} 5$, V. 58 No I.

pausa para quebrar o jejum em algum trecho de praia que houvessem plantado alguns meses antes, após a diminuição da vazão da água. Ali, onde a festa dos visitantes era regada por melancias levemente amadurecidas e amendoins verdes frescos retirados do solo arenoso, o clima festivo prevalecia. Na medida em que uns remavam em seus principais veículos, outros caminhavam pelas praias e pelos atalhos das florestas que atravessam as curvas generosas dos rios, se juntando à canoa no caminho para algum lugar próximo à jusante de Fronteira. Chegando a este ponto, elas obrigavam a canoa a subir o terreno íngreme rapidamente, de modo a percorrer o caminho pela floresta que leva diretamente à aldeia. Caminhando rapidamente para um riacho, paravam para lavar seus corpos suados e vestiam novos vestidos, costurados em máquinas de costura compradas por maridos ou tios na cidade. Os cabelos longos eram penteados e ungidos com o óleo perfumado comercializado por vendedores ocasionais que trafegavam pelo rio ou surgiam na cooperativa da aldeia. Os bebês, por seu turno, voltavam a carregar as atiradeiras, partindo, pois, para a caminhada final em direção ao seu destino.

Vamos imaginar uma visita. Chegando à primeira casa, construída no estilo regional (com piso feito da madeira paxiúba, muito utilizada em palafitas), mas muito maior e mais aberta que as casas dos vizinhos seringueiros não-indígenas, as mulheres percebem que apenas um jovem está em casa, cuidando de seu irmão mais novo. Como eles ficam no pé do tronco entalhado, que serve como uma escada para subir para a casa, a criança recebe cada visitante, individualmente, uma pessoa de cada vez, formalmente: “Min ma huai, Ewan?” ("Você já chega, Mãe?”), ela diz para a mulher que é sua parente classificatória, ou "Min ma ma huai, Yayan? Tsaben?" ("Você já está vindo, minha Sogra? Minha Cunhada?"), ao abordar seus outros parentes classificatórios. As mulheres que visitam respondem sem subir para a sala aberta da grande casa. Em vez de pararem por aqui, elas seguem o caminho que conduz à casa de uma "irmâ" 
CECILIA MCCALlum. ESPAÇO, PESSOA E MOVIMENTO NA SOCIALIDADE...

do líder da expedição que, oportunamente, se encontra presente. Aqui, o grupo se divide. O líder e algumas mulheres e crianças sobem para dentro da casa, enquanto os outros se movem para outro lugar. Os visitantes se sentam de pernas cruzadas sobre uma esteira em um canto da ampla área aberta, enquanto o líder, como o hóspede mais antigo e mais importante, aceita o convite de sua "irmâ" para se reclinar na rede. A anfitriã estende a mesma saudação formal utilizada pela jovem garota para cada visitante. Onde as mulheres não estão relacionadas pelo casamento ou pela consanguinidade, os termos que lhes são endereçados correspondem aos relacionamentos entre os seus kena kuin (nomes reais) 22 . Em resposta à saudação formal "Você está chegando?", cada visitante responde "En huaii" ("Estou chegando"). Em seguida, o anfitrião pergunta: "Min piai hava?” ("Que vais comer?”) A pergunta é retórica. Todos sabem que a dona da casa vai servir comida, mas náo sabem o tipo ou a qualidade dela.

As mulheres se sentam e esperam educadamente enquanto a anfitriâ preenche seu prato com mandioca cozida ou banana verde, talvez cozidos em molho de amendoim ou com nawanti, uma folha verde encontrada na floresta, semelhante ao espinafre. Com uma certa formalidade, ela deposita o seu prato em frente aos visitantes. Eles, no entanto, continuam a esperar. $\mathrm{O}$ momento crítico chega. $\mathrm{O}$ que vem com o prato de vegetais? Felizmente, a dona de casa tem mabex, uma bebida feita de acordo com várias receitas, de preferência com o milho doce, pelo qual os Huni Kuin são famosos. A bebida simboliza piti kuin (comida de verdade), a refeição adequada huni kuin, que é o produto da cooperação homem-mulher no ciclo econômico. Antes de beber mabex, as mulheres aguardam um prato de carne ou peixe ser servido para comer junto (nai-) com a mandioca ou banana. Muitas vezes, a anfitriá pede desculpas - ela não tem nada, só a mandioca, e traz um pouco de sal, talvez manteiga de amendoim ou amendoim torrado em suas conchas para que as mulheres possam comer -nai. Em seguida, elas comem com 
REVISTA DE ANTROPOLOGIA, SÃO PAULO, USP, $20 \mathrm{I} 5$, V. $58 \mathrm{~N}^{\circ} \mathrm{I}$.

gosto, parando apenas para pedir notícias sobre os moradores e contar as suas próprias. $\mathrm{O}$ mabex é servido em uma tigela funda; uma concha de alumínio é fornecida, de modo que cada visitante, um de cada vez, possa recolher a sua parte da bebida.

Se a dona de casa tem um pouco de carne ou peixe escondido na cozinha, ela pode servir generosamente ou pode simplesmente pedir desculpas, fingindo estar desprovida deste suprimento. No entanto, se há uma abundância de caça ou de peixe em casa, é improvável que ela os retenha. À visita especial de boas-vindas também será dado uma porção de carne ou peixe para levar como um presente. A distribuição entre os visitantes nunca é igual, seja de pratos cozinhados servidos para consumo imediato, ou de alimentos cozidos ou crus dados para uso posterior. As normas de hospitalidade exigem que pelo menos um prato esteja disponível para as mulheres poderem compartilhá-lo. Quando a anfitriá quer reforçar uma relação específica, ela seleciona um determinado pedaço, com mais carne e gordura sobre ele, e o entrega com suas próprias mãos diretamente à convidada escolhida. Este ato fortalece os laços entre as duas mulheres. Nestes casos, não há necessidade que a visitante compartilhe com as suas companheiras. Se uma mulher é acompanhada por crianças pequenas, ela os alimenta separadamente com mandioca ou banana e um pedaço de peixe ou um pedaço de carne retirado dos pratos comuns, ou, se for selecionada desta forma, a partir de sua parte particular. Apenas as crianças mais velhas servem-se do prato comum, sob o olhar atento das mulheres adultas, que rapidamente sabem criticar as porçôes inapropriadamente grandes.

Esta refeição servida aos visitantes é similar, em alguns sentidos, às refeiçóes diárias em casa. Há sempre uma certa formalidade no ato de servir alimentos. Quando, por exemplo, os legumes são retirados das panelas e, em seguida, organizados nas travessas, os movimentos adotados são extremamente estilizados, elegantes, poder-se-ia dizer, e algumas 
CECILIA MCCALlUM. ESPAÇO, PESSOA E MOVIMENTO NA SOCIALIDADE...

mulheres se esmeram nesta arte. Algumas são conhecidas por serem boas cozinheiras, preparando cada prato à perfeição, nem cozidos demais, nem muito crus, nem muito grossos e nem muito aguados. Estas cozinheiras famosas são trabalhadoras caprichosas, nunca permitindo que faltem em suas despensas os ingredientes básicos da cozinha huni kuin, o que quase sempre as torna capazes de oferecer uma refeição completa de piti kuin (comida de verdade). Isto é vital caso ela queira arrebatar o prêmio ainbu kuin (mulher de verdade). Se seus maridos e genros são igualmente exímios trabalhadores, caçadores hábeis e, portanto, produtores, estas são, pois, as melhores mulheres para se visitar, pois elas estão mais propensas a serem capazes de servir bem e dar presentes generosos. Na verdade, a capacidade de tratar os hóspedes generosamente em uma refeiçáo completa implica um reforço no seu status como uma ainbu kuin.

Eu me debruço nestes detalhes, porque, do ponto de vista huni kuin, eles são importantes. Talvez, à primeira vista, o ato de preparar e servir comida evoca conceitos como "partilha" simples, a "reciprocidade generalizada" ou leva o observador a considera-los atos domésticos mundanos sem importância sociológica. Entretanto, para os Huni Kuin, o ato de preparar e servir alimentos (ou se recusar a fazê-lo) é parte de uma linguagem sofisticada sobre socialidade, e, como práxis, central a sua constituição. A linguagem de acolhimento, como as palavras homiléticas de um modo geral, opera materialmente, no corpo-mente, efetuando mudanças corporais nas pessoas envolvidas (McCallum, 1990, 1996a, 1996b). A comida, uma vez ingerida, modifica e fortalece o corpo que se torna investido com uma relacionalidade renovada e aguçada. Um aspecto fundamental dessa condição física é a memória direcionada: aqueles que consomem sempre irão se lembrar de como "foram feitos comer" (pima-), nutridos pelos alimentos específicos oferecidos por uma determinada anfitriã. Ao voltar para casa, eles serão capazes de dizer com detalhes o que eles comeram, em que casa, e por quem foram servidos. 
REVISTA DE ANTROPOLOGIA, SÃO PAULO, USP, $20 \mathrm{I}$, V. 58 N $\mathrm{N}^{\mathrm{O}} \mathrm{I}$.

Além disso, nestas trocas cada participante sabe que uma série de interaçóes produtivas vinculadas com outras pessoas e com outras entidades do mundo circundante fez com que tal generosidade se tornasse possível.

Quando as visitantes estão satisfeitas, levantam-se. A anfitriã dá a cada uma das mulheres alguma coisa para que levem consigo, geralmente comida não cozida, como bananas ou mandioca. Assim, ela não só as alimenta, tornando-as mais parentes, menos estrangeiras, mas também fornece o material para que elas "façam comer" (pima-) outros parentes seus. Embora a convenção postule que, normalmente, há que se abster de fazer exigências ultrajantes, as mulheres partem às visitas para transformá-las explicitamente em um ato predatório. As visitantes podem solicitar objetos específicos ou alimentos: "Ea inanve?" (“Dá-me!"). As anfitriâs normalmente não se atrevem a recusar, pois seria o cúmulo da falta de educação, ou pior, uma afirmação de hostilidade aberta.

Essas demandas invertem o sentido mais usual de tais prestaçôes forçadas, que ocorrem quando as pessoas pedem às visitantes de primeira viagem ou parentes de longa ausência, no momento da sua chegada, por um determinado objeto, como um colar, um relógio de pulso ou um par de sapatos. Às vezes, esses "presentes" são simplesmente apropriados quando da confusão de vozes levantadas em saudação aos visitantes, ou da aglomeração de corpos, ou (no caso da longa ausência dos parentes) dos abraços seguidos de lágrimas.

As visitas comuns obedecem a uma dinâmica muito mais contida. No final do dia, os cestos das visitantes já são preenchidos com presentes. Algumas formas da refeição cerimonial acima descrita foram repetidas em até seis ou sete casas que visitei. Em algumas, elas podem ser acompanhadas por uma xícara de café no estilo regional, ou um prato de farinha de mandioca seca. Se for sabido que a despensa está vazia, tais ofertas são aceitas de bom grado. Normalmente, as visitantes são bem informadas sobre quem tem que tipo de caça ou peixe, e assim podem programar 
CECILIA MCCALlUM. ESPAÇO, PESSOA E MOVIMENTO NA SOCIALIDADE...

suas visitas estrategicamente. Quando a anfitriã é tida como mesquinha, as visitantes insatisfeitas comentam em voz baixa quando saem: "Chanichakayamaki. Haven yauxixuki namidan, nuku pimamakidan!" ("Ela mentiu muito. Ela sovinou, escondendo a carne que não nos foi dada a comer!"). Dessa forma, elas sabem que a anfitriã não as considera tão perto, nem deseja torná-las assim.

No entanto, todas reconhecem que toda mulher é capaz de esconder comidas da mesma maneira ao receber uma visita surpresa. Nenhuma mulher é perfeita, generosa - uma "mulher real" - o tempo todo. Assim, há trocas que ameaçam negar certas conexóes, e também há atos que as reconstituem. Ambos são fundamentais para os modos huni kuin de criar relacionalidade. Fazer as "outras" comerem pode ser considerado uma forma de modulação do fluxo de analogia (como Roy Wagner diria), isto porque as tigelas e pratos colocados diante das visitantes falam de um certo grau de conexão que é possível ou intencionado ${ }^{23}$. Eles contêm declaraçóes sobre as capacidades da anfitriã e os seus desejos no que diz respeito ao relacionamento com os convidados. Eles também falam de suas relaçóes passadas e futuras para com os espaços de produção, quais sejam, os roçados, a floresta e os rios ou córregos. Falam, também, sobre suas relaçóes conjugais com o homem que é corresponsável junto com a anfitriá de cuidar e moldar os processos de criação de parentes, seja como $i b u$ de filhos próprios, seja como xanen ibu, homem liderança e assim exíguo produtor. Mesmo servir os tipos mais pobres de alimento contribui para a criação ou manutenção de uma relação e aponta para as relaçóes basais que permitiram tal ato. Do ponto de vista do ciclo de produção, apropriação, compartilhamento e consumo, o ciclo é momentaneamente completo. Ainda que as mulheres partam para os próximos eventos, os fluxos de conexáo já estão habilitados, ativados, por assim dizer, de forma incorporada. Os corpos compostos são os corpos cumulativos dos participantes a conter as capacidades e motivaçóes necessárias para a sua (re)criação futura ${ }^{24}$. 
REVISTA DE ANTROPOLOGIA, SÃO PAULO, USP, $20 \mathrm{I} 5$, V. 58 No I.

\section{Conclusão}

O trabalho explorou as práticas kaxinauá que os constituem como Pessoas Reais (Huni Kuin) enquanto geram socialidade. Mostrou-se que tal autopoiese coletiva ocorre em configuraçóes específicas de tempo e espaço, e que o processo remete a uma teoria material da pessoa que informa as práticas e discursos mundanos, tais como aqueles que acontecem quando um homem sai para caçar, ou um grupo de mulheres sai em visita. A prática material cria as pessoas, tanto as humanas, quanto as não-humanas, e ao mesmo tempo criam-se os contextos que habitam dentro e entre os diferentes níveis do cosmos. Os processos envolvidos forjam relaçóes $i b u$, isto é, as relaçóes metonímicas e assimétricas de apropriação, posse, controle e cuidado as quais não possuem inflexôes de gênero. Homens e mulheres podem igualmente ser donos, parents (do inglês) e cuidadores. O seu trabalho físico ou atividades de predação geram objetos ou pessoas que são suas extensões, ou seja, tem ligaçôes com seus ibu. As ligaçóes entre o produto e o produtor também se estendem, em forma atenuada e temporária, para os lugares onde eles são produzidos, espaços que às vezes são traduzidos para os conceitos de "território" ou "terra". Assim, os Huni Kuin constituem historicamente a relacionalidade em um processo baseado em seu próprio estilo de fenomenologia, que informa as relaçóes sociocosmológicas ao longo do espectro que varia de predação à procriação.

Em vez de derivar a relacionalidade e a energia criativa humana, em primeira instância, de uma ontologia baseada em uma lógica recursiva dualista, neste artigo descrevi como uma forma indígena de fenomenologia é subjacente às relaçôes de posse e controle. Por trás deste argumento está o reconhecimento da centralidade da pessoa para a constituição da relacionalidade, que tem ampla aceitaçáo nos debates da antropologia social sobre os povos da Amazônia (Seeger et al., 1987). No entanto, o presente trabalho procura colocar uma ênfase distinta na noçáo huni kuin de humanidade 
CECILIA MCCALlUM. ESPAÇO, PESSOA E MOVIMENTO NA SOCIALIDADE...

como intrinsecamente ligada à pessoalidade cumulativa (McCallum, 2013). No referido artigo, mostro que a capacidade, o conhecimento e o valor moral são tratados fenomenologicamente como emergindo e afetando as propriedades que são materialmente incorporadas na pessoa ao longo do tempo e extrapoladas no pensamento intencional e na ação prática. Estas emoçôes e ações são ao mesmo tempo epistemológicas e corporais. E, em sendo eventos corporais, eles ligam a pessoa ao tempo e ao espaço da sua própria constituição. No presente artigo, eu sugeri que esse potencial humano propositalmente forma os fluxos de trânsito pela floresta por meio da ação corporal intencional e destes fluxos emerge o mundo como criação humana - casas, vila, jardins, trilhas de caça, dentre outros espaços. Este espaço pode ser temporariamente "possuído", na medida em que a ação humana continua incessantemente a constituí-la. Uma vez que a atividade para - por exemplo, através da morte da ibu (a cuidadora ou dona) - um processo inverso começa, segundo o qual a posse recai novamente no mundo invisível dos yuxin e yuxibu. O yuxin da falecida talvez passe um tempo nesses espaços antes que a memória seja alienada e os vestígios do passado criativo do indivíduo retrocedam. Quando a floresta começa a ser erguer de novo no lugar que era o seu roçado, seu yuxin já se desconectou.

Portanto, "território" huni kuin, a partir deste ponto de vista, não é algo fixo e imutável, mas algo depende da sempre crescente e transformadora copresença da vida produtiva huni kuin. Mesmo que eles obtenham o domínio, por assim dizer, de espaços específicos e recursos produtivos, por meio do engajamento nas relaçóes com os outros seres humanos e outros tipos de corpos e de "pessoas", este domínio só pode ser temporário, na medida em que ele não prescinde da presença e dos esforços físicos. Por esta razão, pode-se dizer, no longo prazo, que os verdadeiros donos da floresta, do céu e do rio são os seres invisíveis desencarnados que o conceito de Diusun evoca. Como Agostinho disse, na epígrafe deste ensaio, a terra está viva por causa do yuxibu que nele vive. 
REVISTA DE ANTROPOLOGIA, SÃO PAULO, USP, $20 \mathrm{I} 5$, V. $58 \mathrm{~N}^{\circ} \mathrm{I}$.

\section{Notas}

1 Baseado na comunicação apresentada no v Congresso da Associação Portuguesa de Antropologia (APA) realizado em Vila Real, Portugal, entre 9 e 13 setembro, 2013, no painel P47: Transformaçóes do espaço ameríndio nas antigas missóes na América do Sul. Coordenação de Susana Viegas (Universidade de Lisboa) e José Glebson Vieira (Universidade do Estado do Rio Grande do Norte). O trabalho também foi apresentado na University of Kent, Canterbury, no Anthropology Seminar, em 3 outubro de 2013. Agradeço à Capes, Coordenação de Aperfeiçoamento de Pessoal de Nível Superior, Brasil, que financiou a visita a Portugal e Inglaterra. O artigo foi traduzido da sua versão original em inglês por Hildon Carade.

2 Professora Adjunta, Departamento de Antropologia, ufba. Honorary Fellow, University of Manchester.

3 Citado em Lagrou (2007: 360; 1998).

4 Aquino (1977), Bakx (1986), Aquino e Iglesias (1994, 1999).

5 Cresce a documentaçáo sobre esse processo linguístico e intelectual entre lideranças e "indígenas cosmopolitas". Ver a obra-mestre de Kopenawa e Albert (2010) para um mergulho no pensamento de Kopenawa, cujas raízes são fincadas na tradição intelectual yanomami, e uma exploração prolongada nas notas de comentários sobre as nuances de significado do seu português.

6 Este comentário é muito mais sugestivo e programático que conclusivo. A utilidade potencial da noção de "poli-ontologia" para a teoria antropológica foi levantada em Scott $(2007,2011)$, quem também lança mão da expressão “ontopraxis”, conceito mais apropriado no contexto dos argumentos desenvolvidos aqui. Agradeço a Olga Ulturgasheva por esta observação. Para uma discussão sobre o uso deste conceito no âmbito da etnografia huni kuin, ver McCallum (2014).

"What goes without saying" - ver Bloch (1992).

8 Uma palavra de cautela: o enfoque nos processos cotidianos que constituem o território como algo contingente não elimina a necessidade de se considerar modos paralelos de relacionamento com a terra, tais como aqueles sugeridos pelo uso de um discurso profundamente enraizado no regime ontológico hegemônico, no contexto das relaçóes interétnicas, uma vez que as questôes referentes à posse da terra no Brasil são determinadas nos termos do referido discurso. No período em que escrevo o artigo, entre 2013 e 2015, o governo brasileiro está empenhado em minar os direitos indígenas à terra, muito embora estes direitos tenham sido consagrados 
CECILIA MCCALlUM. ESPAÇO, PESSOA E MOVIMENTO NA SOCIALIDADE...

pela Constituição de 1988. Ademais, em nome do progresso e do desenvolvimento, apoios têm sido dados àqueles que procuram abolir instituiçóes e garantias que, originalmente, deveriam proteger os povos indígenas. Há uma extensa literatura sobre estes processos coloniais no Brasil. Ver Albert (2005) para uma revisão histórica. Para o caso huni kuin (kaxinauá), ver, por exemplo, as obras citadas em N4.

9 Viveiros de Castro (2001, 2002, 2009); Vilaça (2011); Kelly Luciani (2001). Ver McCallum (2013) para esta discussão. Fora do contexto amazônico, para uma discussão comparativa e reflexão teórica, ver Sahlins (2011, 2012); Pina-Cabral (2012, s.d).

10 Ver Costa e Fausto (2010) sobre a virada ontológica nos estudos ameríndios. Viveiros de Castro, tido como figura chave nesse movimento, dá destaque aos processos sóciocosmológicos na configuração de socialidades para essas populaçôes. Em muitos trabalhos, desenvolveu um modelo estruturalista para tratar do tema do que veio a ser chamado, posteriormente, como relacionalidade. Mais recentemente, ao tratar especificamente do parentesco vivido em vez de privilegiar os aspectos conceituais, ele escreveu: "Amazonian consanguinity is experienced as constructed... more or less along the lines of the current understanding of kinship: in the phenomenal sense of being the outcome of meaningful inter-subjective practices" (A consanguinidade amazônica é experienciada como construída... mais ou menos nos moldes do entendimento atual sobre parentesco: no sentido fenomenal de ser o resultado de práticas intersubjetivas significativas) (2009: 259). Mas, enquanto as relaçóes de "consanguinidade" precisam ser fabricadas, argumenta ele, os povos amazônicos entendem que as relaçóes de afinidade expressam a presença a priori e potencial da alteridade. Assim, reitera um argumento anterior apresentado em Viveiros de Castro (2001, 2002).

11 Tal como Overing e Passes (2000). Para uma discussáo critica em torno do debate sobre as chamadas abordagens substantivistas nos estudos de socialidade na Amazônia, ver McCallum (2013, s.d.).

12 É importante deixar claro que a expressão "fenomenologia indígena”, na medida em que conecta e compara as abordagens indígenas com a fenomenologia - enquanto parte da filosofia europeia -, destina-se a aludir às particularidades da prática e do pensamento amazônico.

13 Arrisco até a dizer que esta forma de tratar as coisas é evocativa da síntese kantiana entre epistemologias empíricas e racionais. Dizendo isso, estou ciente das críticas de Scott (2011) quanto ao perigo de se confundir o não-dualismo filosófico euro -americano com o náo-dualismo indígena. 
REVISTA DE ANTROPOLOGIA, SÃO PAULO, USP, $20 \mathrm{I}$, V. 58 N $\mathrm{N}^{\mathrm{O}} \mathrm{I}$.

14 Ver Lagrou (2007).

15 Evidentemente, ibu remete à categoria de dono-mestre discutido por Fausto (2008), referido por Viegas e outros (nesta coletânea) e discutido na apresentação do dossiê. No entanto, a discussão peca por não contemplar a dimensão de gênero já amplamente documentada na literatura, não só sobre os termos que são traduzíveis como "dono" e/ ou "mãe/pai" entre os Huni Kuin, mas também no caso de outros povos mencionados por Fausto, como oto em kalapalo (Basso, 1973). Esse viés de gênero e a ênfase dada à posse e ao controle ou maestria como paradigmaticamente masculina em Fausto desvia a atenção analítica da importância das relações conjugais na constituição da socialidade e, consequentemente, nos processos históricos de criar territorialidades.

16 Ver Lagrou (2007: 213-215).

17 Kensinger (e mais tarde Deshayes, 1986) estudou a caça huni kuin e as relaçóes entre caçadores, a floresta e os seus seres na região de Curanja nas décadas de 1960 e 1970. As características geológicas e ambientais dos territórios de caça são, sem dúvida, distintas em alguns aspectos significativos daquelas da área Purus, na fronteira do território brasileiro, uma questáo que exige maiores esclarecimentos. Entretanto, não há grandes discrepâncias entre as informaçôes por mim coletadas e as que estes autores levantaram, tampouco a caça é o meu foco nesta pesquisa.

18 Nossa tradução. No original, "Successful hunting requires considerable knowledge of the behavioral characteristics of the animals hunted based on observation. This [...] is 'skin knowledge' bichi una, as is all knowledge of the natural world. When I questioned why it was not 'eye knowledge' [...] they told me that it was knowledge about the jungle's body spirit, yudabake yushin".

19 Não apenas os donos espirituais invisíveis, yuxibu, mas também, de um ponto de vista perspectivista, dos pais ( $i b u)$ das criaturas mortas. Muito tem sido escrito sobre a predação e não é a minha intenção explorar essa literatura em profundidade aqui.

20 A etnografia apresentada nessa seçáo foi publicada em versão anterior, como parte de outro artigo (McCallum, 1998).

21 Uma discussão anterior sobre a etnografia da visita das mulheres, o tópico desta seção, foi apresentada em McCallum (1998).

22 Os Huni Kuin, assim como os Yaminauá, usam um sistema de nomeação que lhes permite identificar a sua relaçáo especifica de parentesco com qualquer pessoa que tenha um nome real. Relativo a nomeaçôes e relacionamentos, ver McCallum (2001).

23 Sobre o parentesco como um fluxo de analogia, ver Wagner (1977).

24 Sobre "cumulative personhood" e o corpo cumulativo, ver McCallum (2013 e s.d.). 
CECILIA MCCALlUM. ESPAÇO, PESSOA E MOVIMENTO NA SOCIALIDADE...

\section{Referências bibliográficas}

Albert, Bruce

2005 "Territoriality, Ethnopolitics, and Development:The Indian Movement in the Brazilian Amazon”. In Surrallés, Alexandre \& Hierro, Pedro García (orgs.), The Land Within: Indigenous Territory and the Perception of the Environment. Copenhagen, Iwgia, pp.200-229.

Aquino, Terri. V. de

1977 Kaxinawá: de Seringueiro "Caboclo" a Peão Acreano. Brasília, dissertação, UnB.

Aquino, T. V. de \& Iglesias, M. P.

1999 Zoneamento Ecológico, Econômico do Acre: Terras e Populaçōes Indígenas. Rio Branco, Instituto do Meio-Ambiente.

1994 Kaxinauá do Rio Jordão: História, Território, Economia e Desenvolvimento Sustentado. Rio Branco, CPI-Acre.

BAKX, Keith

1986 Peasant Formation and Capitalist Development: The Case of Acre, Southwest Amazonia. Liverpool, tese, Liverpool University.

Basso, Ellen B.

1973 The Kalapalo Indians of Central Brazil. Nova York, Holt, Rinehart and Wilson.

BLOCH, Maurice

1992 "What goes without saying: the conceptualization of Zafimaniry society". In Kuper, Adam (org.), Conceptualizing Society. Nova York, Routledge, pp.127-146.

BRown, Michael

1993 "Facing the State, facing the World: Amazonia's native leaders and the new politics of identity". L'Homme. 126-128. XxxIII (2-4): 307-326

Carsten, Janet

2004 After Kinship. Cambridge, cup.

Costa, Luiz \& Fausto, Carlos

2010 "The Return of the Animists: Recent Studies of Amazonian Ontologies". Religion and Society: Advances in Research, 1: 89-109. 
REVISTA DE ANTROPOLOGIA, SÃO PAULO, USP, $20 \mathrm{I}$, V. 58 N $\mathrm{N}^{\mathrm{O}} \mathrm{I}$.

Deshayes, Patrick

1986 "La Manera de Cazar de los Huni Kuin: Una Domesticación Silvestre”. Extracta, n. 5. Lima, CIPA.

Fausto, Carlos

2008 “Donos demais: maestria e domínio na Amazônia”. Mana, 14 (2): 329-366.

KaXinawé, Pancho

2006 "Nossa luta nunca acaba, continua sempre”. In: Papo de Índio, Rio Branco, Acre, domingo, 26 e segunda-feira, 27 de março de 2006. Disponível em Página 20 online: http://pagina20.uol.com.br/26032006/papo_de_indio.htm Acesso em $30 / 05 / 2013$.

Kopenawa, Davi \& Albert, Bruce

$2010 \quad$ La Chute du Ciel. Paroles d'un Chaman Yanomami. Paris, Plon.

Kensinger, Kenneth

1995 How real people ought to live: the Cashinahua of Eastern Peru. Prospect Heights, Waveland Press.

Kelly Luciani, José Antonio

2001 "Fractalidade e troca de perspectivas". Mana, 7 (2): 95-132.

Lagrou, Els M.

2007 A fluidez da forma: Arte, alteridade e ação em uma sociedade amazônica (Kaxinawá, Acre). Rio de Janeiro, Topbooks.

1998 Cashinahua cosmovision: a perspectival approach to identity and alterity. St. Andrews, tese, University of St. Andrews.

McCallum, Cecilia

1990 "Language, Kinship and Politics in Amazonia". Journal of the Royal Anthropological Institute (N.S.) 25: 412-433.

1996a "The Body that Knows: From Cashinahua epistemology to a medical anthropology of Lowland South America”. Medical Anthropology Quarterly, 10: 347-372.

1996 b "Lenguaje, parentesco y política”. In SAntos Granero, Fernando (org.), Globalización y cambio en la Amazonía indígena. Quito, Abya-Yala - Flacso, v. 1, pp. 47-88.

1997 "Comendo com Txai, comendo como Txai: A sexualização de relações étnicas na Amazônia contemporânea”. Revista de Antropologia, 40: 109-147. 
CECILIA MCCALLUM. ESPAÇO, PESSOA E MOVIMENTO NA SOCIALIDADE...

1998 "Alteridade e sociabilidade Kaxinauá: Perspectivas de uma antropologia da vida diária”. Revista Brasileira de Ciências Sociais, vol. 13, n. 38: 127-136.

2001 Gender and Sociality in Amazonia: How Real People are Made. Oxford, Berg.

2013 "Intimidade com estranhos: uma perspectiva kaxinawá sobre confiança e a construção de pessoas na Amazônia”. Revista Mana, vol. 19, n. 1: 123-155.

2014 "Cashinahua perspectives on functional anatomy: Ontology, ontogenesis, and biomedical education in Amazonia”. American Ethnologist, vol. 41: 504-517.

s.d. "Trustworthy Bodies: Cashinahua Cumulative Persons as Intimate Others". In Ystanes, Margit \& Broche-Due, Vigdis (orgs.), Intimacy, Trust and the Social: Tensed Relations. Berghahn, no prelo.

Oliveira, João Pacheco de

1998 "Uma etnologia dos 'índios misturados'? Situação colonial, territorialização e fluxos culturais”. Mana, 4/1: 47-77.

Overing, Joanna \& PAsses, Alan

2000 "Introduction". In ___ (orgs.), The Anthropology of Love and Anger: the Aesthetics of Conviviality in Native Amazonia. Londres: Routledge, pp.1-30.

Pina-Cabral, João

2012 "The two faces of mutuality: contemporary themes in anthropology". Anthropological Quarterly, vol. 86, n. 1: 257-276.

s.d. Kinship as company: A contemporary summary.

SAHLIns, Marshall

2011 "What is Kinship? Part Two", JRAl, (N.S.) 17: 227-242.

2012 What Kinship Is- And Is Not. Chicago, Univ. of Chicago Press.

Scotт, Michael

2011 "Steps to a methodological non-dualism. For the Motion”. In Debate: Nondualism is Philosophy not Ethnography. Manchester.

2007 The Severed Snake: Matrilineages, making place and a Melanesian Christianity in Southeast Solomon Islands. .Durham - NC, Carolina Academic Press.

Seeger, Anthony; DaMatta, Roberto \& Viveiros de Castro, Eduardo

1987 [1979] "A construção da pessoa nas sociedades indígenas brasileiras". In PACHECO DE Oliveira, João (org.), Sociedades Indígenas \& Indigenismo no Brasil. Rio de Janeiro, UfRJ, Editora Marca Zero. 
REVISTA DE ANTROPOLOGIA, SÃO PAULO, USP, $20 \mathrm{I}$, V. 58 N $\mathrm{N}^{\mathrm{O}} \mathrm{I}$.

VILAÇA, Aparecida

2011 "Dividuality in Amazonia: God, the Devil, and the constitution of personhood in Wari' Christianity." JRAI (N.S.), 17(2): 243-262.

Viveiros de Castro, Eduardo

2009 "The gift and the given: three nano-essays on kinship and magic". In BAMFORD, S. C. \& LeACH, J. (orgs.), Kinship and Beyond: The Genealogical Model Reconsidered. Nova York, Oxford, Berghahn Books.

2002 A Inconstância da Alma Selvagem. Rio de Janeiro, Cosac Naify.

2001 "GUT feelings about Amazonia: potential affinity and the construction of sociality”. In Rival, L. \& Whitehead, N.L. (orgs.), Beyond the Visible and the Material. Oxford, oup.

1998 "Cosmological Deixis and Amerindian Perspectivism". Journal of the Royal Anthropological Institute, (N.S.) 4: 469-88.

1996 "Os Pronomes Cosmológicos e o Perspectivismo Ameríndio". Mana: Estudos de Antropologia Social, 2(2): 115-144.

WAGNER, Roy

1977

"Analogic kinship: A Daribi example". American Ethnologist, 4: 623-642. 
ANTROPOLOGIA URBANA...: ENTREVISTA COM GRAÇA ÍNDIAS CORDEIRO

\section{Space, Personhood and Movement in Amerindian Sociality: on Huni Kuin Modes of Sociality}

ABSTRACT: The article explores Huni Kuin practices that simultaneously constitute sociality, persons and their relationship with the environment. When creating themselves in a material and social sense in inter-subjective processes occurring in specific space-time configurations, they forge contingent connections of ownership between people and places, and create the conditions to open temporary clearings of human space in a world guarded and cared for by non-human entities. The article begins by recalling the commitment of Huni Kuin leaders to defending their ownership rights and insisting on the demarcation of indigenous lands, as specified by Brazilian law, for which they use a non-indigenous discursive language. The main focus of this essay, however, is on indigenous practices of everyday life. It explores the notion that, in an important sense, for this Amazonian people, territory is not fixed, but depends on the constant transformation of the co-presence of Huni Kuin who are involved in relationships with each other and with other entities and persons from the surrounding world.

KEYWORDS: Space, Sociality, Territory, Amazonian Socio-cosmology, Cashinahua.

Recebido em outubro de 2014. Aceito em março de 2015. 